\title{
EFP Structure Optimal Design for Satellite Attack through Air-space Platform
}

\author{
Chi Junxiang, Cheng Hua, Dong Kangsheng and Weng Xingwei \\ Aeronautics and Astronautics Engineering College, Air Force Engineering University, \\ Xi'an, CHINA 710038 \\ chijunxiang126@126.com
}

\begin{abstract}
Air-space combat is the inevitable tendency for future war. Building weapon system on spacecraft is prerequisite for passive defense and active attack. Considering limited space and constrained posture adjust ability, this paper established a weapon system by installing EFP (explosively formed penetrator) warhead and the optimal design of EFP structure. Several critical technologies related to EFP design were studied, an optimal design project of EFP warhead structure war acquired after constructing mathematic models and numerical simulations, which can effectively solve the critical technical difficulties of constructing weapon system on spacecraft.
\end{abstract}

Keywords: Air-space combat, EFP, satellite attack, optimal structure design, numerical simulation

\section{Introduction}

Natural unity of aviation and spaceflight is the essence qualification of air-space integration battle and the basis of air-space strategy. Entering 21 century, aerospace assault system consists of airplane, ballistic missile, near space vehicle, spacecraft and quickly forming atmosphere striding vehicle. Air-space attack comes from vertical space is becoming the main threat to national safe. Air-space combat force based on net becomes the main body of national strategic defense, lead role of joint operation, main force of strategic strike and pioneer of strategic fast reaction. Space of aviation and spaceflight has become strategic highland of national safe and development, so if the country forwarding to dominate the air-space it has to forestalling possess its own air-space strategy. Satellite`s attack from air-space platform through EFP is an effective method to strive for air-space strategy.

\section{Idea of EFP Warhead Design}

EFP warhead is an important method to target's effective attack through high speed [1-2], high temperature and high pressure. How to effectively form size controllable pills is the key technology of target's destroy. EFP warhead design involves EFP shaping mechanism, charge design, liner material, detonation model, etc. The design purpose is to make the liner possess reasonable shape, big length-diameter ratio, high density, good trajectory performance and strong penetration ability when it explodes. There is 't any design standard because of the complicated EFP shaping process and 
many influencing factors, to make a good design of EFP warhead and improve work efficiency, both right design idea and research method are required.

Beginning in middle 1980s, comes to the deep research stage of EFP warhead, significant progresses have made in the design idea and integrated design method combined with many design means is began to be adopted, which greatly improves research efficiency [3-5]. In present, three design methods are extensively adopted, they are approximate formula or experience method, one-dimension two-dimension or three dimension code numerical modeling method and experimental method, among those methods the reachable design precision gradually increases. When initiate design project is predicted by present method, the latter method will be adopted to make the design. If any defect appears in advanced design that indicates the insufficiency of original design, then return to lower level to make a redesign, this process will repeat many times till a satisfies design result is gained. The specific design flow diagram is shown in Figure 1.

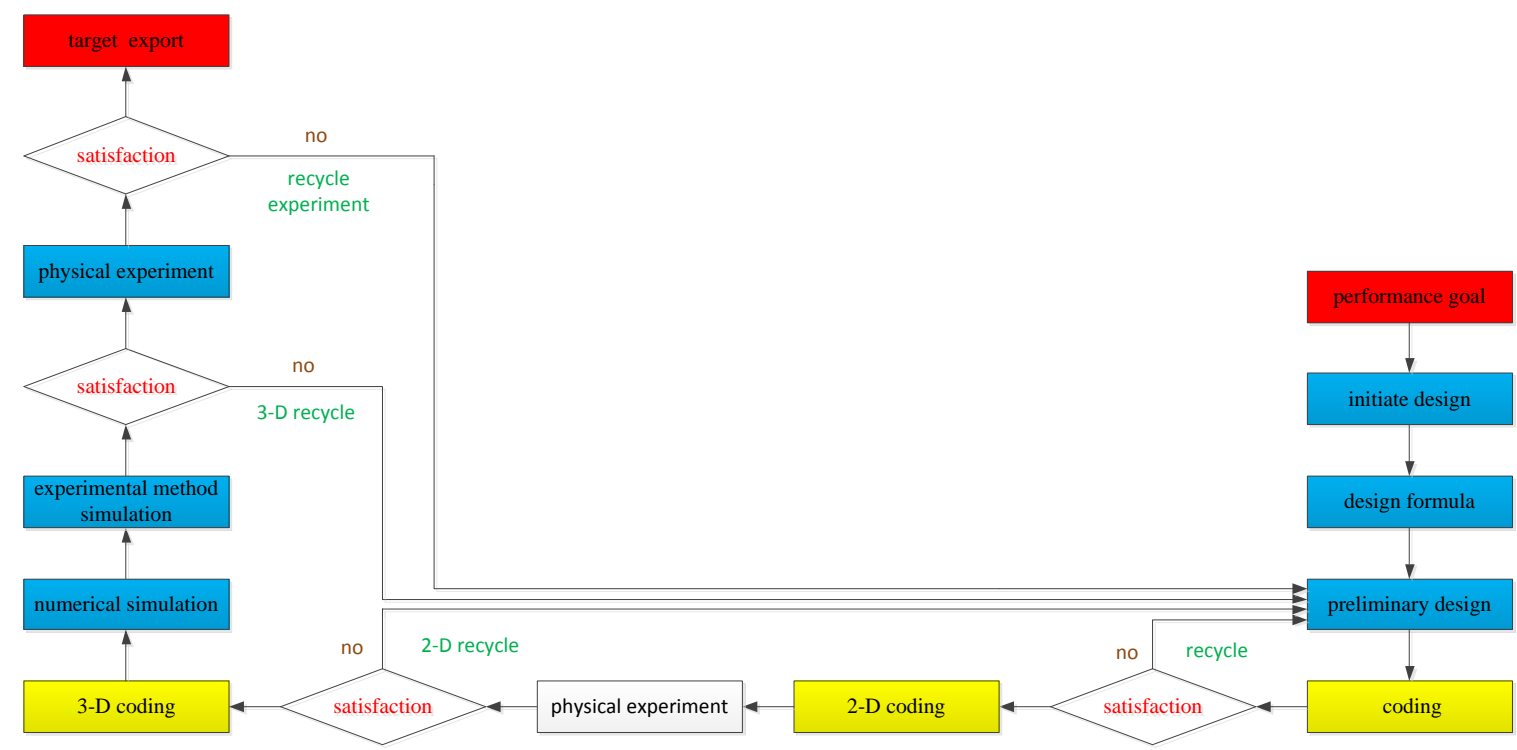

Figure 1. EFP Design Flow

\section{Relative Model of EFP Warhead Design}

\section{1) Explosive model}

Explosive uses high-explosive-burn model, expanding of the detonation product uses JWL (Jones-Wilkens-Lee) state equation [7]. Presuming spread speed of detonation front is constant, state equation expresses by pressure $\mathrm{P}$ of explosive detonation product is:

$$
p=A\left(1-\frac{\omega}{R_{1} V}\right) e^{-R_{1} V}+B\left(1-\frac{\omega}{R_{2} V}\right) e+\omega \rho e
$$


Of which, $V=\frac{\rho_{0}}{\rho}, \rho_{0}$ is explosive initiate density, $\rho$ is detonation production density, $e$ is specific internal energy, other parameters are experimental fitted parameters.

Requirements of EFP warhead explosive can divide into detonation performance requirements, technique performance requirements and storage requirements. Main requirements of explosive detonation performance are the explosion pressure and explosion speed, because penetration depth linearly increases with the increase of explosion pressure and explosion speed. Technical requirements for explosive are good shape performance in normal condition, no mold sticking, good fluidity, low sensitivity of impact, friction and static electricity. Explosive long-term storage requirements are does not decompose, produce no corrosive gas or ion, and make no corrosion to liner and object.

To meet above requirements, usually explosive used in EFP warhead are compacte mixed explosive 8701, which is mainly combines of hexogen(RDX) and octogen (HMX); cast B explosive and JH-2 TNT-RDX explosive, which are compound of TNT and RDX or HMX. Wu Jun figures out after numerical simulation that energy transferred by 8701 explosive detonation wave is bigger than of compound B during interaction between detonation wave and liner, so we can get bigger speed and length-diameter ratio from 8701 explosive than that from B explosive in the same condition.

According to factory process condition and available material, this paper respectively researched cast charge and compact charge. Compact explosive uses mixture explosive mainly consist of RDX, cast explosive includes B explosive and RDX/TNT (JH-2 TNT-RDX explosive) [8]. 8701 explosive is high explosive with a very high initiate detonation pressure which is far higher than that of $\mathrm{B}$ explosive, because B explosive detonation energy release is relatively smaller than that of 8701 explosive. Function time is very short between detonation wave and flyer during the detonation-driven process, initiate pressure has a great affect to the speed of flyer. Therefore, 8701 explosive was selected as the final design project.

Table 1. B Explosive Constants

\begin{tabular}{cccccccc}
\hline$\rho_{0}$ & $P$ & $e$ & $\mathrm{~A}$ & $\mathrm{~B}$ & $R_{1}$ & $R_{2}$ & $\omega$ \\
\hline 1.171 & 29.5 & 8.5 & 524.23 & 7.678 & 1.1 & 4.2 & 0.34 \\
\hline
\end{tabular}

Table 2. 8701 Explosive Constants

\begin{tabular}{cccccccc}
\hline$\rho_{0}$ & $P$ & $e$ & $\mathrm{~A}$ & $\mathrm{~B}$ & $R_{1}$ & $R_{2}$ & $\omega$ \\
\hline 1.787 & 34.0 & 9.0 & 581.41 & 6.8 & 4.1 & 1.0 & 0.35 \\
\hline
\end{tabular}

Table 3. JH-2 explosive Constants

\begin{tabular}{cccccccc}
\hline$\rho_{0}$ & $P$ & $e$ & $\mathrm{~A}$ & $\mathrm{~B}$ & $R_{1}$ & $R_{2}$ & $\omega$ \\
\hline 1.700 & 30.0 & 10.0 & 564.21 & 6.801 & 4.1 & 1.3 & 0.36 \\
\hline
\end{tabular}




\section{2) Charge size design}

The design purpose of explosive charge is to fully make use of detonation efficiency and decrease explosive dosage under the condition that liner can form expected EFP as designed. Initiate speed of EFP greatly increases as length-diameter ratio increases, $0.5 \sim 1.5$ is normally rational to length-diameter ratio. Main charge storage is designed to be cylinder to be convenient for charging in development stage, charge diameter equals to liner diameter, length-diameter ratio of charge respectively to be $0.80,0.85,0.90,0.95,1.00$. Length-diameter ratio finally determine to be 1.00 after numerical simulation and experiment optimization, and tail of main charge storage is designed to be truncated cone-shape in order to cut down invalid charge.

\section{3) Liner model}

Normally, metal liner uses Steinberg constitutive model and Gruneisen state equation. Shear modulus $\mathrm{G}$ and yield stress $\sigma_{Y}$ both increase as pressure increases and decrease as temperature decreases, both nearly to be zero when they come to material melt temperature [9-10].

Material shear modulus before melt,

$$
\begin{aligned}
G & =G_{0}\left[1+b p v^{1 / 3}-h\left(\frac{e-e_{c}}{3 R^{\prime}}-300\right)\right] \exp \left(-\frac{f_{e}}{e_{m}-e}\right) \\
\sigma_{Y} & =\sigma_{0}\left[1+b^{\prime} p v^{1 / 3}-h\left(\frac{e-e_{c}}{3 R^{\prime}}-300\right)\right] \exp \left(-\frac{f_{e}}{e_{m}-e}\right)
\end{aligned}
$$

Of which, $G_{0}, \sigma_{0}, b, b^{\prime}, h, f$ are material parameters; $p$ is pressure, $v$ is specific volume, $e$ is internal energy, $e_{c}$ is cold reduction energy, $e_{m}$ is melt energy, $R$ is common gas constant, $\rho$ is density, $A$ is mole quality.

Gruneisen state equation,

$$
p=\frac{\rho_{0} c_{0}^{2} \mu(1+\mu)}{[1-(s-1 \mu)]^{2}}+\gamma\left[\rho e-\frac{\rho_{0} c_{0}^{2} \mu^{2}}{2[1-(s-1) \mu]^{2}}\right]
$$

Of which, $\mu=\frac{\rho-\rho_{0}}{\rho_{0}}, \gamma=2.02, c_{0}$ and $s$ are straight line intercept and slant-range of Rankine-Hugongiot, and respectively $c_{0}=3.94 \mathrm{~km} / \mathrm{s}, \mathrm{s}=1.49$ 。

EFP shaping condition:

$$
\left\{\begin{array}{l}
\beta=e^{k} \\
k=-0.1 \alpha(\lambda-0.228)^{2}+0.029 \alpha+4.49(\lambda-0.16)^{2}+2.83
\end{array}\right.
$$

Johnson-Cook constitutive model expression:

$$
\sigma=\left(A+B \varepsilon^{p n}\right)\left(1+C \ln \varepsilon^{*}\right)\left[1-\left(\frac{T-T_{\text {room }}}{T_{m}-T_{\text {room }}}\right)\right]
$$

Of which, $\mathrm{A}, \mathrm{B}, \mathrm{C}, \mathrm{n}, \mathrm{m}$ are material constants; $\varepsilon^{p}$ and $\varepsilon^{*}$ are equivalent plasticity strain and strain rate, $T_{m}$ is melt temperature, $T_{\text {room }}$ is indoor temperature. 
Table 4. Model Performance Constants of Different Material

\begin{tabular}{ccccccccc}
\hline material & $\begin{array}{c}\rho_{0}( \\
\left.g / \mathrm{cm}^{3}\right)\end{array}$ & $\begin{array}{c}\mathrm{G} \\
(\mathrm{Mba})\end{array}$ & $\begin{array}{c}\mathrm{A} \\
(\mathrm{Mba})\end{array}$ & $\begin{array}{c}\mathrm{B} \\
(\mathrm{Mba})\end{array}$ & $\mathrm{N}$ & $\mathrm{C}$ & $\mathrm{M}$ & $\begin{array}{c}T_{m} \\
(\mathrm{k})\end{array}$ \\
\hline \multirow{2}{*}{ copper } & 8.96 & 0.460 & $\begin{array}{c}0.90 \times \\
10^{-3}\end{array}$ & $\begin{array}{c}2.92 \times \\
10^{-3}\end{array}$ & 0.31 & $\begin{array}{c}0.02 \\
5\end{array}$ & $\begin{array}{c}1.0 \\
9\end{array}$ & 1356 \\
\hline \multirow{2}{*}{ aluminum } & 2.785 & 0.276 & $\begin{array}{c}2.65 \times \\
10^{-3}\end{array}$ & $\begin{array}{c}4.26 \times \\
10^{-3}\end{array}$ & 0.34 & $\begin{array}{c}0.01 \\
5\end{array}$ & $\begin{array}{c}1.0 \\
0\end{array}$ & 775 \\
\hline \multirow{2}{*}{ iron } & 7.806 & 0.818 & $\begin{array}{c}7.92 \times \\
10^{-3}\end{array}$ & $\begin{array}{c}5.10 \times \\
10^{-3}\end{array}$ & $\begin{array}{c}0.01 \\
4\end{array}$ & $\begin{array}{c}0.01 \\
4\end{array}$ & $\begin{array}{c}1.0 \\
3\end{array}$ & 1793 \\
\hline
\end{tabular}

Liner performances of Material density, strength and plasticity condition straightly affect EFP shaping and penetration power. Different material in same structure produces different EFP. Liner material used to make backward-turn shaping must have the characters of big density, good plasticity, high speed, proper strength and high melting point, etc. EFP with higher material density gets higher specific kinetic energy in the same speed, which helps to deeper armour penetration. Material with good plasticity is not easy to produce flaw during machining and assures no breakage appear during dynamic stretch, which does good to EFP shaping. Sole melt material and alloy material such as industrial pure iron, red copper, aluminum and silver and so on are usually made use of to make EFP warhead liner. Based on performance contrastive analysis to above material, ductility of red copper is better than that of industrial pure iron, Red copper is the best economic liner material to make the EFP warhead which requires high stand-off and big length-diameter ratio. Therefore, this paper selected red copper to be the basic material for liner.

\section{EFP Optimizing Design Project}

Parameters that affect EFP warhead performance mainly are liner structure and material, charge type and structure, detonation wave front shape and body etc. So the design and shaping of EFP should consider these above factors. The basic question to analyze EFP shaping is the calculating of crushing speed and direction at every point on liner, liner quality distribution and total momentum, because pill shaping process can be forecast through these parameters. To grasp main contradiction and enhance theoretical calculate reliability, simplified physical model of EFP warhead is applied, speed distribution and quality distribution along the generatrix of liner are calculated, which provides a relatively clear and accurate physical graph and calculation result. For these reasons, spherical liner is employed in this paper for EFP warhead and to make further discussion.

Liner structure size, charge length-diameter ratio and liner hole size are design objects under the assumption that charge type and liner material are invariant. Liner inner surface curvature radius $r_{1}$, outer surface curvature radius $r_{2}$, liner depth $\delta$, charge length-diameter ratio $\mathrm{N}$ and liner top hole diameter $r$ are five mainly considered factors in orthogonal optimal design. Because the design is for preventive weapon on air-space platform, charge should be as little as possible to reduce recoil. 
And because the space of air-space platform is limited, charge length-diameter ratio $\mathrm{N}$ should be as small as possible according to the reality. After several optimal design calculations, factors scope were narrowed step by step on the basis of really application condition, which makes design level tend to be more rational.

Table 5. Constants of Different Orthogonal Design Level

\begin{tabular}{llllll}
\hline factors & $\delta$ & $\mathrm{N}$ & $r$ & $r_{1}$ & $r_{2}$ \\
\hline Level 1 & 1.00 & 0.80 & 4.80 & 34.5 & 29.5 \\
\hline Level 2 & 1.05 & 0.85 & 4.90 & 35.0 & 30.0 \\
\hline Level 3 & 1.10 & 0.90 & 5.00 & 35.5 & 30.5 \\
\hline Level 4 & 1.15 & 0.95 & 5.10 & 36.0 & 31.0 \\
\hline Level 5 & 1.20 & 1.00 & 5.20 & 36.5 & 31.5 \\
\hline
\end{tabular}

EFP speed and specific kinetic energy acquired by simulating calculation were used to be the optimal design evaluate index. Orthogonal table $L_{25}\left(5^{5}\right)$ was used to arrange 25 levels related to 5 factors, and 25 numerical calculation projects were achieved, detail information are in table 5 and table 6.

Table 6. Orthogonal Optimal Design Calculation Project

\begin{tabular}{llllll}
\hline $\begin{array}{l}\text { sequence } \\
\text { number }\end{array}$ & $\delta$ & $\mathrm{N}$ & $r$ & $r_{1}$ & $r_{2}$ \\
\hline 1 & 1.00 & 0.80 & 4.80 & 34.5 & 31.5 \\
\hline 2 & 1.00 & 0.85 & 5.00 & 35.0 & 29.5 \\
\hline 3 & 1.00 & 0.90 & 5.20 & 35.5 & 30.5 \\
\hline 4 & 1.00 & 0.95 & 4.90 & 36.0 & 30.0 \\
\hline 5 & 1.00 & 1.00 & 5.10 & 36.5 & 31.0 \\
\hline 6 & 1.05 & 0.85 & 4.90 & 34.5 & 30.5 \\
\hline 7 & 1.05 & 0.90 & 5.10 & 35.0 & 31.5 \\
\hline 8 & 1.05 & 0.95 & 5.00 & 35.5 & 29.5 \\
\hline 9 & 1.05 & 1.00 & 4.80 & 36.0 & 30.0 \\
\hline 10 & 1.05 & 0.80 & 5.20 & 36.5 & 31.0 \\
\hline 11 & 1.10 & 0.90 & 5.00 & 34.5 & 31.0 \\
\hline 12 & 1.10 & 0.95 & 5.20 & 35.0 & 31.5 \\
\hline 13 & 1.10 & 1.00 & 4.90 & 35.5 & 29.5 \\
\hline 14 & 1.10 & 0.80 & 5.10 & 36.0 & 30.5 \\
\hline 15 & 1.10 & 0.85 & 4.80 & 36.5 & 30.0 \\
\hline 16 & 1.15 & 0.95 & 5.10 & 34.5 & 30.5 \\
\hline 17 & 1.15 & 1.00 & 4.90 & 35.0 & 31.5 \\
\hline
\end{tabular}




\begin{tabular}{llllll}
\hline 18 & 1.15 & 0.80 & 5.20 & 35.5 & 30.0 \\
\hline 19 & 1.15 & 0.85 & 5.00 & 36.0 & 31.0 \\
\hline 20 & 1.15 & 0.90 & 4.80 & 36.5 & 29.5 \\
\hline 21 & 1.20 & 1.00 & 5.20 & 34.5 & 30.5 \\
\hline 22 & 1.20 & 0.80 & 5.00 & 35.0 & 29.5 \\
\hline 23 & 1.20 & 0.85 & 4.90 & 35.5 & 31.5 \\
\hline 24 & 1.20 & 0.90 & 5.10 & 36.0 & 30.0 \\
\hline 25 & 1.20 & 0.95 & 4.80 & 36.5 & 31.0 \\
\hline
\end{tabular}

Finite element simulating calculation model was constructed based on warhead structure project (see table 6), numerical simulating calculation of above-mentioned 25 warhead design projects were separately taken through finite element process LS-DYNA. EFP speed V and specific kinetic energy E were acquired from simulation results, and optimal structure parameters of EFP charge was obtained through range analysis and synthetical balance analysis.

Table 7. Numerical Simulation Table

\begin{tabular}{lll}
\hline $\begin{array}{l}\text { sequence } \\
\text { number }\end{array}$ & $\mathrm{V} /\left(\mathrm{ms}^{-1}\right)$ & $E /\left(\mathrm{Jmm}^{-2}\right)$ \\
\hline 1 & 2380 & 50.18 \\
\hline 2 & 2412 & 61.23 \\
\hline 3 & 2485 & 58.56 \\
\hline 4 & 2501 & 60.15 \\
\hline 5 & 2522 & 60.98 \\
\hline 6 & 2445 & 63.46 \\
\hline 7 & 2358 & 62.15 \\
\hline 8 & 2296 & 54.19 \\
\hline 9 & 2415 & 54.17 \\
\hline 10 & 2488 & 56.18 \\
\hline 11 & 2308 & 71.23 \\
\hline 12 & 2321 & 65.23 \\
\hline 13 & 2354 & 50.23 \\
\hline 15 & 2301 & 45.26 \\
\hline 16 & 2208 & 40.15 \\
\hline 17 & 2210 & 59.87 \\
\hline 18 & 2207 & 52.17 \\
\hline
\end{tabular}


International Journal of Signal Processing, Image Processing and Pattern Recognition Vol.8, No.9 (2015)

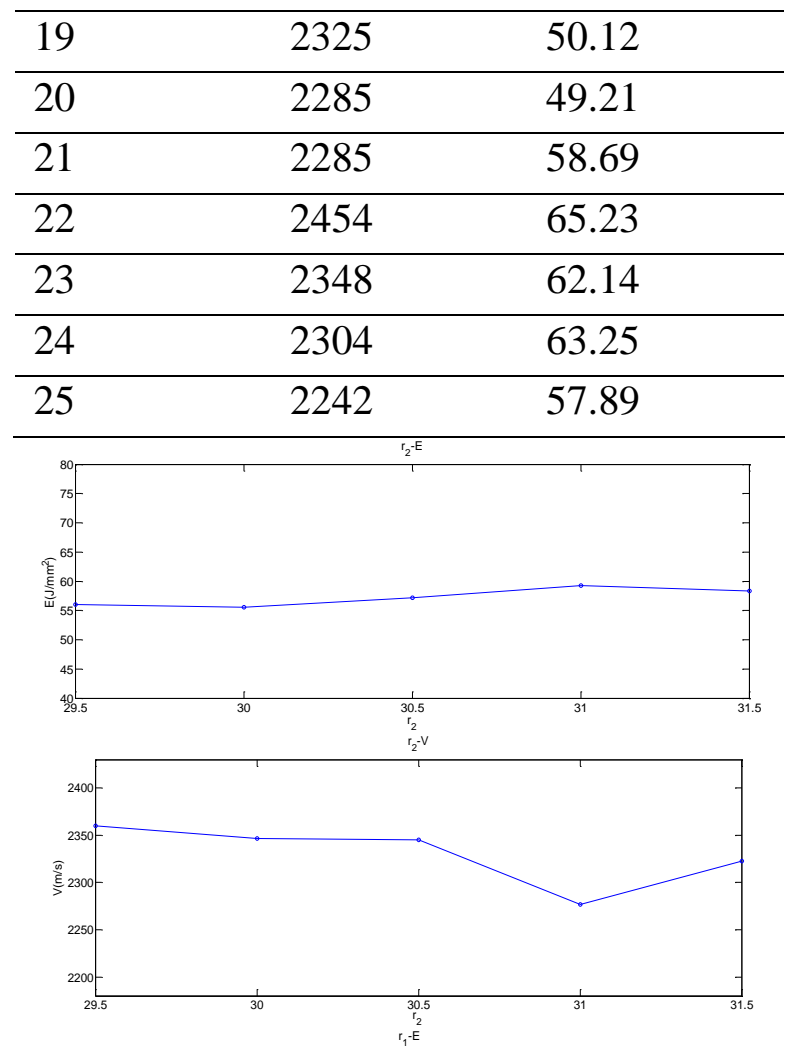
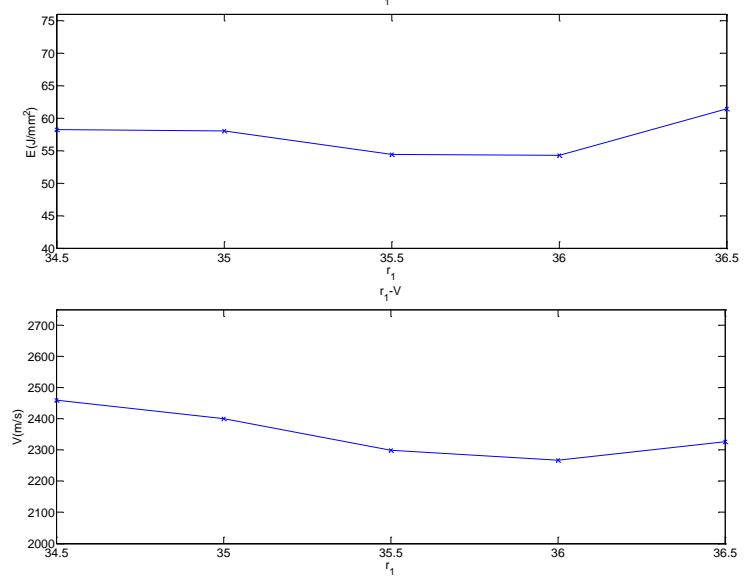

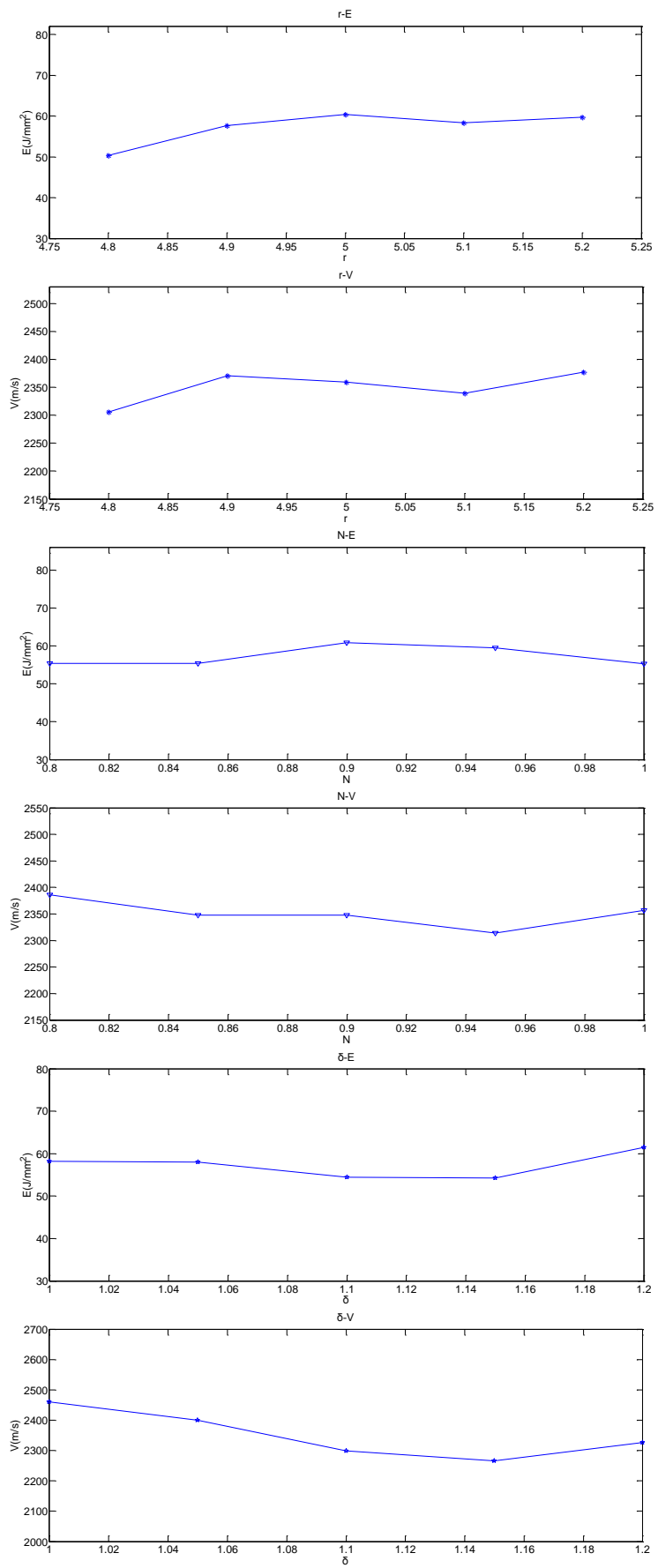

Figure 2. EFP Speed and Specific Kinetic Energy Changing Curves Follow Many Factors

Knowledge gets through simulation data and rang analyzing,

$1 \delta$ is the most important factor to $\mathrm{V}$ and is the main index, but least important to $\mathrm{E}$; 
2、 $r$ makes both affect to $\mathrm{V}$ and $\mathrm{E}$, relatively larger $\mathrm{V}$ and $\mathrm{E}$ can be got when it approaches to $0.14 r_{1}-0.15 r_{1}$;

3、 bigger $r_{1}$, smaller $\mathrm{E}$ and bigger $\mathrm{V}$;

4、 bigger $r_{2}$, bigger $\mathrm{E}$ and smaller $\mathrm{V}$;

5、 bigger $\mathrm{N}$, both $\mathrm{V}$ and $\mathrm{E}$ are bigger, the best value for $\mathrm{N}$ is 1.0.

Based on above analysis, the optimal design project is $\delta=1.05, N=1.0$, $r=4.90, r_{1}=35.5, r_{2}=31.0$.

Simulation test was conducted on the basis of optimized design project, and simulation results of speed $\mathrm{V}$ and specific kinetic energy $\mathrm{E}$ were got. The results obviously show that the shaping parameters of optimized project are better than that of above-mentioned 25 projects.

Table 8. Optimal Numerical Simulation Table

\begin{tabular}{ccc}
\hline $\begin{array}{c}\text { sequence } \\
\text { number }\end{array}$ & $\mathrm{V} /\left(\mathrm{ms}^{-1}\right)$ & $E /\left(\mathrm{Jmm}^{-2}\right)$ \\
\hline $\begin{array}{c}\text { optimized } \\
\text { project }\end{array}$ & 2598 & 76.05 \\
\hline
\end{tabular}

X-ray testing is an effective approach to acquire EFP warhead shape and speed parameters, to test the rationality and availability of numerical simulation this paper proposed, relational parameter tests were token based on normal X-ray test method. Simulation result can provide basis for further parameter calculating optimal adjustment and test the correctness of parameters calculated by numerical simulation in parent sample.

Test result of $\mathrm{X}$-ray, $\mathrm{V}=2507$. Test result shows that relative error between numerical simulating calculation value and $\mathrm{X}$-ray test value is $3.5 \%$, less than allowance error 5\%, which demonstrates that numerical simulation is in accordance with the test. The designed optimal project in this paper is rational and results of numerical simulating calculation can provide basis parent sample to X-ray test.

\section{Conclusions}

Simulation result shows that a combination method of orthogonal design and numerical simulation this paper proposed is efficient to EFP warhead structure parameter optimal design. Relationship between EFP warhead structure design parameters and EFP speed V and specific kinetic energy E are acquired through simulation and range analysis. Further research direction is to design an EFP warhead with smaller recoil.

\section{References}

[1] Q. Zhang, D. Yao and L. Cao, "Preparation and Formability of Tungsten-Copper EFP Liner", RARE METAL MATERIAL AND ENGINEERING, vol. 3, no. 38, (2009).

[2] W. Yang, C. Jiang and Z. Wang, "Experimental Study and Numerical Simulation on EFP Based on VESF Initiation”, CHINESE JOURNAL OF HIGH PRESSURE PHYSICS, vol. 5, no. 27, (2013). 
[3] R. Fong, W. Ng and W. Tang, "Multiple explosively formed penetrator(MEFP) warhead technology development", $19^{\text {th }}$ International Symposium on Ballistics,2001; Interlaken, Switzerland.

[4] A. Blache and K. Weimann, "Multi EFP charge for lightweight armor defends", 18th International Symposiumon Ballistics, 1999; San Antonio, USA.

[5] Livemore Software Technology Corporation, LS-DYNA Version 971 Keyword User`s Manual. Livemore Software Techonlogy Corporation, (2007).

[6] W. Jia, H. Shi and Q. Zhang, "Ordnance Material Science \& Engineering, vol. 1, no. 29, (2006).

[7] T. Zhao, H. Luo and W. Jia, "Ordnance Material Science \& Engineering, vol. 1, no. 29, (2007).

[8] Held M. 20 ${ }^{\text {th }}$ Int Symp on Ballistics, 2002; Orlando, FL.

[9] R. Shi, G G. Xu and J P. Xu, "Numerical simulation of energy output structure for underwater explosive", Chinese Journal of Energetic Materials, vol. 2, no. 17, (2009).

[10] R. Fong, W. Ng and S. Tang, "Multiple explosively formed penetrator warhead technology for mine and improvised explosive device neutralization", $22^{\text {th }}$ International Symposium on Ballistics, 2005; Vancouver, Canada.

\section{Author}

Chi Jun Xiang, he is a PH.D candidate of Air Force Engineering University, in Xi an. Research interest is EPF structure design and unmanned aerial vehicle auto-attack. 
International Journal of Signal Processing, Image Processing and Pattern Recognition Vol.8, No.9 (2015) 